report of the Home Office working party of which I was a member. You omitted reference to the Institute of Psychosexual Medicine, whose training method was quoted in the consultative document as a possible model for other workers (pp 70, 58, 61).

This method had its origins 25 years ago in a Balint research group under the auspices of the Family Planning Association, from which the institute took over responsibility four years ago. Thus for almost a quarter of a century we have trained primary care doctors in the treatment of sexual and marital difficulties. Training is by in-service group case discussion so that doctors treat their own patients in their own setting from the outset. The practical, empirical therapeutic approach so acquired may be used to treat a variety of psychosomatic problems also, so that its application is much broader than the more recently published behavioural techniques for simple dysfunctions of sexual performance. In addition to employing these skills in their everyday surgery or clinic practice, more than 300 doctors have during these years acquired sufficient expertise to accept referrals from other practitioners and agencies. The institute grants a certificate of competence in psychosexual medicine to such doctors, who are required to satisfy an examining panel that they have reached the required standard by clearly defined criteria.

Some 40 primary care doctors have so far developed sufficient additional skills to become trainers themselves in their own areas of the British Isles (and one in Australia). Since the formation of the institute four years ago some 500 new doctors have come into training, approximately half of whom are general practitioners.

Prudence Tunnadine Director of training, Institut
of Psychosexual Medicin

London W1N $1 \mathrm{DG}$ Home Office, Marriage Matters. A Consultative
Document by the Working Party on Marriage Guidance. London, HMSO, 1979.

SIR,-I have combined motherhood and medicine for the last 20 years and am reminded daily in both roles of the need to comprehend the whole person-it seems impossible to separate the emotions of the individual from the bodily state.

My work in medicine, after the inevitable sequence of odd jobs a part-time medical graduate finds herself doing, has led via family planning practice to an almost full-time involvement in psychosexual medicine. It seems that the presenting symptom of marital disharmony is very often sexual dysfunction. However, what is a psychosomatic manifestation of the marital distress often engages the doctor's attention. The patient expects the doctor to cure the physical symptom and often hopes that help will be found for the sexual and marital problem. He selects the doctor carefully as being a suitable person whom he trusts and with whom rapport may already exist. The doctor feels inadequate or ill equipped or too short of time to respond and may refer the patient. I find that many patients are lost by referral. The doctor appears to have endorsed the difficulty or insolubility of the problem and the patient often feels unable to face this unknown expert and confess. If in fact he does get to the expert his and the referring doctor's expectation of magic are unrealistically high. Sometimes the initial interview with the doctor of the patient's choice has more therapeutic value than the doctor recognises.

It seems to me that the doctor the patient has selected is the one who should feel able to listen. This may be the patient's genera practitioner or the family planning doctor most commonly. These are the doctors who should develop the necessary skills to comprehend the whole patient. If these skills can be acquired in this field only through supervised work then the Balint-style seminar is admirably suited to this shared learning process. There are such seminars in this country under the auspices of the Institute of Psychosexual Medicine, which seeks to set standards in this area of medicine. Money to train the trainers is often hard to come by from local authorities, which can see the need to finance physical medicine but have little to spare for long-term good housekeeping.

The Marriage Guidance Council has an important role to play in this area of distressed relationships but often seems also to feel il equipped to respond to the physical component of the client's distress, particularly sexual. To delegate this fundamental aspect of doctoring to a voluntary body when it belongs where the patient put it, in the doctor-patien setting, seems to me to be a terribly retrograde step for the medical profession.

Larger government investment is needed for training if marriage really matters (5 May, p 1164), but surely it should be used for the basic training of doctors so that the need for specialists and other experts becomes less. Then the patient will have a chance of keeping mind and body together.

Leeds, W Yorks

JOAN COOMBS

\section{Premature rupture of the membranes}

SIR,-Y Your leading article on premature rupture of the membranes (5 May, p 1165) deals with an important perinatal problem, but we would challenge one point.

The quoted $40^{\circ}$ incidence of intrauterine infection 72 hours after membrane rupture seems higher than that generally experienced in Britain. We agree that management should include "judicious induction of labour to strike a balance between the risks of fetal immaturity and those of infection associated with conservative management." However, it is dangerous to equate maturity, which in this context signifies functional maturation of the fetal lungs, with either a particular gestational age or a specified birth weight. We therefore challenge the suggested policy of immediate induction of labour when the membranes have ruptured at 34 or more weeks' gestation, or when the fetus is judged (how?) to weigh at least $2000 \mathrm{~g}$. Your leader rightly states that "we have no reliable means of knowing when the fetus is at risk from infection," but it is now possible to assess fetal pulmonary maturation with considerable accuracy.

Although the incidence of respiratory distress syndrome (RDS) is small after 36 weeks of gestation, there was an overall incidence of $18^{\circ}$. in five studies reviewed by one of us (MJW), and Usher et $a l^{1}$ reported that the mortality from RDS in babies of this gestational age was about $6 \%$. Labour will often ensue within a week after membrane rupture at between 34 and 36 weeks, but each additional day in utero at that stage will increase the likelihood that the fetal lungs will be safely mature at birth. If therefore, in the absence of an over-riding maternal indication, delivery prior to 36 (or perhaps even 37 ) weeks is contemplated, it is essential first to determine the functional state of the fetal lungs by estimation of the lecithin: sphingomyelin ratio (or other surfactant test) in the amniotic fluid. The sample for testing can usually be obtained by high vaginal aspiration, but transabdominal amniocentesis may occasionally be needed.

C R WHITFIELD M J WhittLe

Department of Midwifery Queen Mother's Hospital,

\section{Glasgow G3 8SH}

Usher, R H, Allen, A C, and McLean, F H, American

\section{Nutrient intake}

SIR,-Professor Harry Keen and his co-workers claim (10 March, $p$ 655) that the less people eat the heavier they are, and the more sugar they eat the lower the concentration of their fasting blood glucose. These unexpected conclusions are valid only if they used a reliable and reasonably precise method of assessing both energy intake and sugar intake. Surprisingly, although their paper gives their results in a number of tables and graphs, the methods by which they made their dietary assessments-the basis on which all their calculations and conclusions rest-are insufficiently described in a very few lines.

It appears that subjects were asked to describe their diet for periods of one, two, or three days, and clearly the three-day weighment method recommended by the International Biological Programme ${ }^{1}$ as the acceptable minimum for assessment of individual food intake was not employed. Other methods of dietary assessment are notoriously inaccurate, and Acheson (1975) showed that even among subjects who were concurrently weighing their food the 24-hour recall underestimated energy intake by some $16^{\prime \prime}$. Much of the error is attributable to omission of snack foods and drinks, many of which contain sugar, and the degree of inaccuracy will vary both with the food pattern and with the composition of the diet.

It may be that the authors managed, despite these sources of error, to achieve a degree of precision and reliability that other workers have not been able to achieve. If so, it is reasonable to ask why they have not demonstrated this by describing how they have validated their method of dietary intake.

Pamela Mumford Elizabeth Evans

Department of Nutrition Queen Elizabeth College,

International Biological Programme, Handbook No 9.
Oxford, Blackwell Scientific Publications, 1969. Acheson, K J, British Antarctic Survey Bulletin, 1975 , 41-2, 87 .

SIR,-In their paper on nutrient intake, adiposity, and diabetes Professor Harry Keen and others (10 March, p 655) interpret the highly statistically significant but small negative correlation between total energy intake and body mass index (BMI) as one between energy intake and adiposity. However, this may be an artefact of using BMI as a measure of adiposity.

If, as is suggested by some authors, ${ }^{1-3}$ there is a negative correlation between BMI and height, the taller subjects in the study would tend to be towards the left of the published scatter diagram (smaller BMI) and the shorter towards the right, leading to the alternative 